\title{
Target detection distances under different road lighting intensities
}

\author{
Sanaz Bozorg Chenani ${ }^{1}$ (D) Matti T. Vaaja ${ }^{1,2} \cdot$ Matti Kurkela $^{1,2} \cdot$ \\ Iisakki Kosonen ${ }^{1} \cdot$ Tapio Luttinen ${ }^{1}$
}

Received: 22 September 2016 / Accepted: 10 March 2017 / Published online: 27 March 2017

(C) The Author(s) 2017. This article is published with open access at SpringerLink.com

\begin{abstract}
Purpose Road lighting illuminates road surface and surrounding areas of objects on a road, while car headlights illuminate vertical objects on a road. The goal of the study was to investigate the interaction between road lighting and car headlights at target detection distance.

Method Target detection distances under different road lighting intensities and car headlights were studied with and without glare from an oncoming car. Dimmable high-pressure sodium lamps with three lighting levels 49, 71 and $100 \%$ (3557, 5179 and $7252 \mathrm{~lm}$ ) were used. Test drivers had to detect a small uniform standard target standing vertically on the straight road.

Results In the absence of glare (low beam car headlights), road lighting intensity levels of 100 and $49 \%$ provided comparable detection distances, while at $71 \%$ of road lighting intensity visibility was the lowest. The target was seen in negative or positive contrast in $100 \%$ of road lighting. In $71 \%$ of road lighting, the target was detected in positive contrast. While, in $49 \%$ of road lighting target was seen in negative contrast. There was a significant difference in detection distances under different road lighting intensities when there was no glare from the oncoming car. The significance main effect was between 49 and $71 \%$ of road lighting intensities. In addition, no significant differences in the effect of road lighting intensities could be found under glare from the oncoming
\end{abstract}

Sanaz Bozorg Chenani

sanaz.bozorgchenani@aalto.fi

1 Department of Built Environment, Aalto University, Otakaari 4, 02150 Espoo, Finland

2 Centre of Excellence in Laser Scanning Research (CoE-LaSR), School of Engineering, Aalto University, Espoo, Finland car. In the presence of glare from the oncoming car, targets were always in negative contrast. Both road lighting and car headlights are associated with detection distances.

Conclusion The results of these experiments can give new insight to the development of intelligent road lighting considering the combined effect of road lighting and car headlights. The results provide useful insight to dim the lighting in order to save energy without impairing the detection of objects.

Keywords Detection distance $\cdot$ Road lighting $\cdot$ Car headlights $\cdot$ Combined effect $\cdot$ Dimming $\cdot$ Traffic safety

\section{Introduction}

Road accidents have been ranked in top ten causes of death, accounting for $2.2 \%$ of all deaths globally [21]. Such accidents are often caused by a combination of human, roadway, and vehicle factors accounting for 57,3 , and $3 \%$, respectively. The rest is due to interactions between them [2]. One countermeasure factor in the number and severity of road accidents is road lighting $[8,11]$. Several studies have indicated that the accident risk is higher at night than during the day $[11,16]$. Artificial lighting plays a crucial role in reducing the accident risk. The effect of road lighting on the number of accidents has been studied extensively $[8,11,19]$. A comprehensive review by CIE [8] concluded that road lighting reduces night-time accidents for all road types (rural, urban and freeways, and intersections and interchanges) by $30 \%$ on average. However, road lighting consumes a lot of energy. Worldwide, in 2005, $8 \%$ of total lighting electricity was consumed by road lighting amounting to about $218 \mathrm{TWh}$ [13].

Perception requires a luminance or colour contrast between target and its background. To create contrast and to provide better visibility and safe driving during night, artificial light by 
road lighting or car headlights is needed. Car lights are more effective in illuminating vertical surfaces, whereas road lighting is targeted to the illumination of roads on horizontal or road surface directions [6]. Illuminance on the road is divided into three distinct zones based on illumination by car and road lighting: near, intermediate and distant zones $[4,6]$. Car headlights are dominant in the near zone (10 to $40 \mathrm{~m}$ from car headlights). The role of both car headlights and road lighting is approximately equal in the intermediate zone (40-60 m from the car), however, the combination of these lights may not be efficient in detecting all objects in this zone. In the far zone (beyond $60 \mathrm{~m}$ from the car), road lighting is dominant, increasing the visibility of the road surface at far distances. Road lighting at the distances beyond the range of car headlights improves drivers' comfort by enhancing the detection of objects in the far zone and allowing the anticipation of road geometry at far distances. Therefore, the role of both car headlights and road lighting is essential in detecting objects on the roads at different distances $[4,6]$.

The research to date has tended to focus on the efficiency of road lighting and car headlights separately and little is known about the interaction between these two lights [6]. An experimental study by Bacelar [5] indicated that road lighting is sufficient for visibility of targets. Adding car headlights did not improve the visibility of targets on the road. This was explained by a decrease in the contrast between the target area and the road surface due to the cumulative effects of headlights and luminaires. Ekrias et al. [10] indicated that low beam car headlights reduced target contrasts and, thus, had a negative effect on target visibility. They noted that the effect of car headlights was highly dependent on the position of the car, target and road surface reflections, car headlights, the geometry of the lighting installations, a target location in relation to luminaries, and weather conditions [10]. However, drivers can rely on car headlight illumination to detect objects on the road even if road lighting is not available.

High electricity consumption and related costs of road lighting are the driving forces for new and efficient road lighting technology to tackle energy, cost, and safety challenges. Thus, a transition to intelligent road lighting systems is expected in the near future. Such technology dims light based on real time conditions to comply with the demand. A question that needs to be addressed, however, is what intensity level of road lighting provides the best visibility. Bacelar [5] studied the influence of dimming the road lighting on visibility. $\mathrm{He}$ assessed the target visibility under different road lighting illuminations $(100,75,50$ and $25 \%$ of luminous flux with an average illuminance of $31.5,23.6,15.7$ and $8.7 \mathrm{~lx}$ or average luminance of $2.45,2.24,1.53$, and $0.73 \mathrm{~cd} / \mathrm{m}^{2}$, respectively). The targets were placed in 10 different positions, and the observers stood facing away from the targets under different road lighting conditions. After turning around, they had to grade the visibility of the targets. The results indicated that dimming up to $50 \%$ did not have a significant influence on visibility. He also noted that the position of the targets on the road had more impact on visibility than the dimming. However, he did not consider the effect of car headlights.

Car headlights should not be switched off due to safety factors, whereas road lighting can be dimmed up to the level where drivers' visual performance is not compromised due to the combined effect of car headlights and road lighting. To date, very little research has been done on the combined effect of road lighting and car headlights on drivers' visual performance. A study by Bozorg Chenani et al. [7] on the combined effect of dimmed road lighting and car headlights indicated that reducing road lighting intensity is feasible in the presence of car headlights with and without the effect of glare from an oncoming car. However, the effect of dimming of the road lighting was not monotonic. Also, the study was conducted in a stationary car. In addition, previous studies indicated that car headlights are sufficient for safe driving with the speed of up to $50 \mathrm{~km} / \mathrm{h}[14,20]$. Thus, one can conclude that reducing road lighting in urban areas with low speeds might be workable. But there has not been any study on the combined effect of dimmed road lighting intensities and car headlights in a moving car.

The present study seeks to determine the combined effect of different road lighting intensities and car headlights on detection distances. The impact of glare from an oncoming car on detection distances was also investigated.

\section{Material and Methods}

These measurements are a follow-up measurement on the previous article by Bozorg Chenani et al. [7]. They performed a measurement in a stationary car in two scenarios with/without glare from an oncoming car. In the former measurement, the distance of the car was constant $80 \mathrm{~m}$ between the target and the car; and in the latter, the distance of the glare source to the measurement car was $70 \mathrm{~m}$ (the targets were $10 \mathrm{~m}$ behind the glare source). The target was placed on a grid of 15 positions between two poles. Visibility of the target and the effect of disability glare on the visibility were evaluated based on participants grade, and luminance measurement (to evaluate contrast and visibility level by Adrian model). Overall, 360 gradings were collected. The results indicate that reducing road lighting in the presence of car headlights is feasible.

These experiments were performed to determine the effect of different road lighting levels on target detection in dynamic driving conditions. The experiments were conducted on a two-lane straight road section in Otaranta, Finland. This place was selected because it had a quiet environment to perform the experiments and ability to dim the light by adjusting the supply voltage. The road section was approximately $300 \mathrm{~m}$ long and $6 \mathrm{~m}$ wide. The road had markings. 
Procedure One standard target was vertically placed on the road surface in the middle of two poles, and in the centreline of the lane in the position that is shown in Fig. 1. This position was selected as a critical position in the lane. In this position, very little light from both luminaires shone directly on the face and back of the target, and preliminary measurements had indicated that this position had the least illumination and least visibility [7].

Participants Five drivers participated in the experiments: three males ( 2 of them 30 years old, with the heights of $175 \mathrm{~cm}$ and $189 \mathrm{~cm}$, and one 50 years old, height $176 \mathrm{~cm}$ ) and two females (one 30 years old, height $158 \mathrm{~cm}$ and one 50 years old, height $183 \mathrm{~cm}$ ). The participants had valid driver's licenses. Participants having visual impairment wore eyeglasses to satisfy the visual requirement for driving. Participants were instructed equally about the procedure of the experiment. The number of participants was low, because the measurements were conducted in one night. Also, in the previous study by Bozorg Chenani et al. [7] it was found that the perceived visibility of a target from a stationary car correlated well with measured contrast and the Adrian model. The visibility was, however, not a monotonic function of road lighting level [7]. In this study, the measurements of the previous study have been extended to a moving-car set-up. The number of participants was small, but the previous study indicated that the results were consistant and compatible with theoretical measures.

Before the experiment, participants were directed to the test cars and familiarised with the procedures. Also, to make the conditions similar for all scenarios, participants made a test drive before the experiment to learn the procedure and the position of the target. The measurement layout at the detection distance point is displayed in Fig. 1.

Test drivers drove at the speed of $30 \mathrm{~km} / \mathrm{h}$ (inner city speed and the speed limit of the street), and they pressed a button immediately when they detected the target. Each driver had to detect one target in each round. Drivers were changed in each round to avoid order effect. Three lighting intensities were used in the order of 100,49 , and $71 \%$. For each lighting level, the measurements were performed in two parts: 1) in the first part of the experiment, the drivers had to detect the target in no glare condition (low beam car headlights) and 2) then in the same road lighting level, the drivers had to detect the target in a glare condition (low beam car headlights and glare from the oncoming car). This was repeated for each lighting level so that each driver had to detect the target six times. Altogether 30 distance detections were measured.

Distance detection was performed using a Nikon D700 camera with a wired remote control and a measuring tape mounted on the road surface. ISO speed 200 and the aperture $\mathrm{f} / 5.6$ were used. Camera movement was avoided by using a flash with a short exposure time (1/3200 s) and its shutter lag was 40 milliseconds.

The camera was pointed towards the measuring tape, which was placed on the road surface. The camera was located outside of the car, approximately at the same distance from the target as the driver's head. Drivers pressed the remote switch button when he/she observed the target on the road surface. When the button was pressed, the camera took a picture of the measuring tape, which displayed the distance to the target. The accuracy of the distance measurement method was estimated to be approximately $\pm 10 \mathrm{~cm}$. Possible sources of inaccuracy could be the camera orientation related to driver and the possible noise in the camera remote control delay.

Driver's reaction time may vary depending on the situation (alerted or surprise situation). Wortman and Mathias [22] found 0.9 and $1.3 \mathrm{~s}$ perception-reaction time for alerted and surprised situations, respectively. Reaction time was not considered because under all scenarios it was assumed to be similar for each participant.

Otaranta road geometry was measured with a Faro Focus 3D terrestrial laser scanner. The distance measurement accuracy was $\pm 2 \mathrm{~mm}$ at a distance of $25 \mathrm{~m}$. The road was measured
Fig. 1 Schematic layout of experiment field in detection point. Luminance refers to luminous intensity per unit projected area. $\mathrm{L}_{\mathrm{b}}$ refers to the background luminance and $\mathrm{L}_{t}$ refers to the target luminance

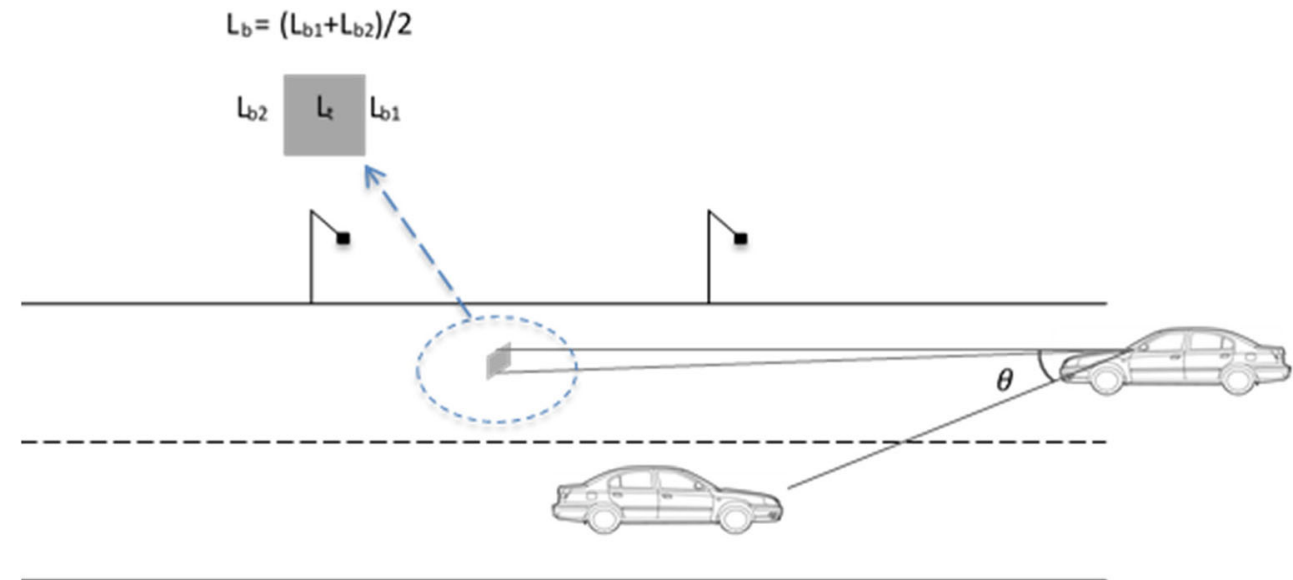


from four separate scanning positions. The objective of the measurements was to obtain a comprehensive description of the road geometry. Figure 2 depicts the profile view of the TLS measurement on the Otaranta road.

The luminaires were installed on one side of the road. The spacing between poles was $32 \mathrm{~m}$ with the mounting height of $10 \mathrm{~m}$. Each luminaire had one $100 \mathrm{~W}$ High-Pressure Sodium (HPS) light source. Characteristics of the luminaires and information about the dimming of the luminaires are listed in Table 1.

The luminous flux of the light source could be adjusted in order to dim the lighting. To examine the effects of dimming the experiments were performed with 100, 71, and $49 \%$ light source intensities, which were equal to 230,210 and $190 \mathrm{~V}$ supply voltage, $7252 \mathrm{~lm}$, and $5179 \mathrm{~lm}$, and $3557 \mathrm{~lm}$, respectively.

Table 2 displays the horizontal illumination of the road surface at target locations under different road lighting intensities:

Cars The cars used in the experiments were Volkswagen Golf (model 1990) and Volkswagen Polo (model 1999). Both cars had Halogen headlights, Volkswagen Polo had H7 lamps, $50 \mathrm{~W}$ and $1500 \mathrm{~lm}$, and Volkswagen Golf had H4 lamps $55 \mathrm{~W}$ and $1000 \mathrm{~lm}$. Volkswagen Polo was used as the main car, and Volkswagen Golf was used as a stationary car to produce glare. The target was located $10 \mathrm{~m}$ behind the glare source. During the experiments, there was no traffic, which reduced the complexity and workload of driving compared to real conditions. Road lighting in Otaranta could be classified as class M5 according to the classification system in CIE 115:2010 [9]. Regulations of car headlights (i.e., luminous intensity, light distribution, and location of the headlight) are based on the Economic Commission for Europe (ECE) [6].

Target One standard $20 \mathrm{~cm} \times 20 \mathrm{~cm}$ uniform flat square vertical target with a reflection factor of 0.50 was used. The target corresponded to Small Target Visibility (STV), which is difficult to observe on a road surface $[10,17]$.

It was not possible to completely rule out the possibility that drivers used some triggers to help them locate the target. In order to keep the lighting conditions unchanged, the target location had to be fixed and could not be randomised. However, because of the vertical curvature of the street, the
Table 1 Characteristics and dimming information of the luminaires with different percentages of luminous flux

\begin{tabular}{llll}
\hline & $100 \%$ & $71 \%$ & $49 \%$ \\
\hline Luminous flux (lm) & 7252 & 5179 & 3557 \\
Voltage (V) & 230 & 210 & 190 \\
Power (W) & 111 & 90 & 72 \\
$\mathrm{CCT}^{*}(\mathrm{~K})$ & 1931 & 1921 & 1906 \\
$\mathrm{Ra}^{*}(\mathrm{Ra})$ & 21.1 & 12.9 & 7 \\
\hline
\end{tabular}

${ }^{*} \mathrm{CCT}$ is correlated colour Temperature ${ }^{\mathrm{a}}$, Ra is colour-rendering index ${ }^{\mathrm{b}}$

${ }^{\text {a }}$ Correlated Colour temperature (CCT) defined by CIE is "the temperature of the Planckian radiator whose perceived colour most closely resembles that of a given stimulus at the same brightness and under specified viewing conditions". a description of the warmth or coldness of a light source the unit of CCT is Kelvin. The lower colour temperature refers to warmer and reddish colour of light and the higher colour temperature refers to the cooler and more bluish colour of light

${ }^{\mathrm{b}}$ Colour rendering index is the ability of a light source to accurately render all frequencies of its colour spectrum when compared to a perfect reference light of a similar type. It is rated on a scale from 1 to 100 . The lower the CRI rating, the less accurately colours will be reproduced

drivers were not able to fix their eyes on the location before the target emerged in the visual field. Also, the aim of the study was not to find the absolute detection distances but to compare the effects of road lighting levels on detection distances.

A target can be detected by colour or luminance contrast. In night time driving colour vision is poor and detection is mainly by the difference in luminance between target against its background. Contrast can be either positive or negative. The former refers to the brighter target against a darker background, and the later refers to darker target on a brighter background.

The Weber contrast formula (1) is normally used to measure the contrast of a target against its background [18]:

$C=\frac{L_{t}-L_{b}}{L_{b}}$

In the equations, $L_{t}$ and $L_{b}$ are the luminance of target and background as shown in Fig. 1. The contrast would be negative when $L_{b}>L_{t}$ (ranges from -1 to 0 ) and positive when $L_{t}>L_{b}$ (ranges from 0 to infinity). A contrast of equal absolute value with either positive or negative sign do not yield equal

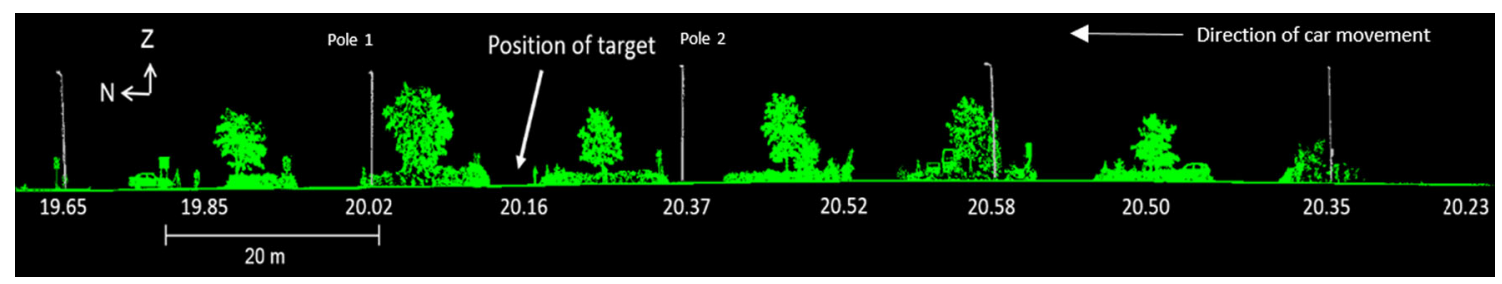

Fig. 2 Profile view of the TLS measurement on the Otaranta Street, the numbers are road heights 
Table 2 Horizontal illumination of the experiment point in different lighting levels

\begin{tabular}{ll}
\hline & $\begin{array}{l}\text { Illumination of target } \\
\text { point }\left(\mathrm{lm} / \mathrm{m}^{2}\right)\end{array}$ \\
\hline $100 \%$ & 2.8 \\
$71 \%$ & 1.6 \\
$49 \%$ & 1.4 \\
\hline
\end{tabular}

visual performance. A dark target on a light background (negative contrast) is detected sooner and with more distinguishable detail than a light target on a dark background (positive contrast) with the same absolute value of minimum luminance difference [12]. Therefore, it is complex to estimate driver performance. To solve this, a redefined contrast formula (Eqs. 2 and 3) is introduced in which contrast is equal to an absolute value of the difference between target and background luminance divided by the larger of the two luminances. This alternative definition of contrast provides absolute contrast value, and it indicates equal visual performance for both positive and negative contrasts [10]. This formula is used when there is no glare [18]:

$C=\frac{\left|L_{t}-L_{b}\right|}{\max \left(L_{b}, L_{t}\right)}$

The contrast of objects is reduced in the presence of glare due to the extra light. The effect of extra light in the visual field that causes a decrease in visibility is called veiling luminance. If the veiling luminance, equivalent luminance of stray light in the eye, is added to both background and target luminance, Therefore, the amount of contrast when the driver is affected by glare can be calculated by Eq. (3):

$C=\frac{\left[\left(L_{t}+L_{v}\right)-\left(L_{b}+L_{v}\right)\right]}{\left(L_{b}+L_{v}\right)}=\frac{L_{t}-L_{b}}{L_{b}+L_{v}}$

The amount of veiling luminance depends on the illumination of glare source, the age of the observer, and angle of the glare source [1,15] as shown in Eq. (4):

$L_{v}=\frac{k \times E_{\text {glare }}}{\theta^{n}}$

Where

$k=9.05\left[1+\left(\frac{\text { age }}{66.4}\right)^{4}\right]$

$n= \begin{cases}2.3-0.7 \log \theta, & 0.2^{\circ}<\theta<2^{\circ} \\ 2, & \theta>2^{\circ}\end{cases}$
In the equations, $L_{v}$ is veiling luminance, $E_{\text {glare }}$ refers to the illumination of glare source to the eye in lux, $\theta$ is the angle of the glare source, angle between the line of sight and the centre of the glare source, in degrees. It is for the fixation line of $1^{\circ}<\theta<30^{\circ}$ from the line of sight of the drivers and the $k$ is the age-dependent factor, and age is the age of observer in years. The contrast of the targets was calculated based on the conditions at the moment of target detection using measured target and background luminance.

Analysis of variance (ANOVA) with repeated measures was used for statistical tests because the same drivers participated in all experiments. Three tests were used: the first one is a two-way ANOVA method and it tested the effect of different road lighting intensities (with three levels: 100, 71, and 49\%) and car headlights (glare/no glare). The second one tested the effect of different road lighting in no glare scenario. Finally, the effect of different road lighting in the presence of glare from an oncoming car was tested.

\section{Results}

The mean detection distance under different road lighting intensities is shown in Fig. 3. It indicates that results are consistent, and there seem to be no major interaction effects. The target was detected from longer distances when there was no glare from the oncoming car. The distances were slightly shorter when headlights from the oncoming car affected the driver.

It is difficult to get accurate target contrast data during driving because the contrast is changing all the time for the driver. However, the provided data in Table 3 gives a rough estimate of the contrast at the detection locations. The contrast was found based on Eqs. 2 or 3 and the sign in parentheses indicates positive or negative contrast. The results indicate that target was seen in either positive or negative contrast under $100 \%$, while under $71 \%$ of road lighting drivers saw the target in positive contrast (less distance from target) and negative contrast under $49 \%$ of road lighting intensity. In addition, under glare from an oncoming car, the contrast was always negative due to the extra light from an oncoming car.

The current study focuses on the intermediate and far zones (introduced by [6]) and explained in the introduction) where the combined effect of road lighting and car headlights is effective (40 $\mathrm{m}$ and beyond).

As it can be seen from Fig. 4, reducing road lighting intensity reduces the combined vertical illumination on the target. The reduction is noticeably greater when reducing from 100 to $49 \%$ than when reducing from 100 to $71 \%$. Unlit (off road lighting) condition could not be done on the same road due to safety aspects. However, vertical illumination in off situation was measured on another road with the same pavement characteristics. The vertical illumination measurements indicate 
Fig. 3 The mean detection distance of all drivers under different road lighting intensities

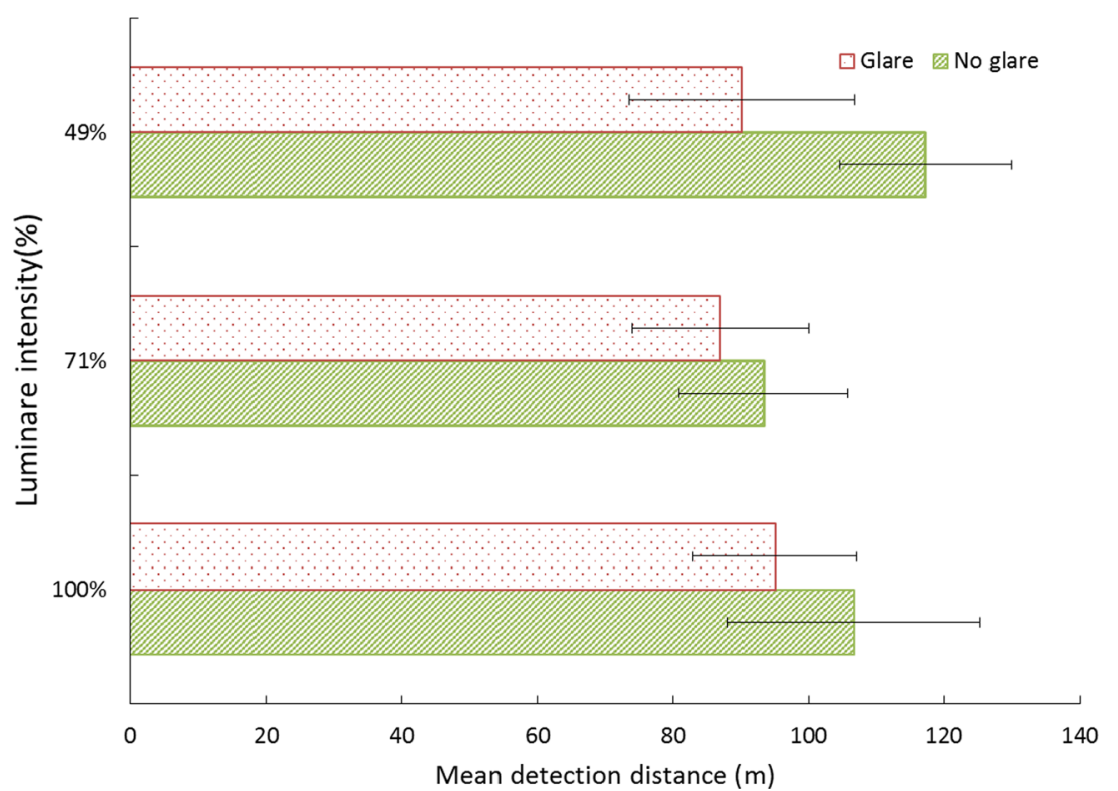

similar results with previous studies by Boyce [6] and Bacelar [4]. As Fig. 4 indicates, the effect of car headlights drops distinctly at the distance of $60 \mathrm{~m}$ and beyond, which is known as the far zone.

Although vertical illumination indicates the effect of road lighting and car headlights on the target, it does not determine how visible the target is. Other important factors are distance, size of the target, contrast of the target against its background and luminous uniformity of the background. Figure 5 presents the negative and positive contrast provided by combined effect of different road lighting intensities and car headlights at different distances. Lower road lighting intensities provide better contrast than the full road lighting up to the distance of $70 \mathrm{~m}$ because at lower road lighting intensities the effect of car headlights will be increased. From the distance of $70 \mathrm{~m}$ to $100 \mathrm{~m}$, the effect of different road lighting intensities on the contrast tends to be similar. This is because the effect of car headlights was reduced gradually and the luminance of the target and background was comparable. From $110 \mathrm{~m}$ above different road lighting intensities provide negative contrast. In that a negligible amount of light reaches the target from car headlights, thus the presence of road lighting increases negative contrast and contrast generated by different road lighting intensities diverges. Full road lightings provide the slightly better absolute value of contrast than lower road lighting intensities. The contrast was levelled out from $120 \mathrm{~m}$ for $49 \%$, and $150 \mathrm{~m}$ for 100 and $71 \%$ road lighting intensities, because at long distances car headlights had no significant effect and higher road lighting provide better negative contrast.

Statistical analyses were conducted to test the significance of the differences in detection distance under different road lighting intensities and glare/no glare headlights. The significance level was 0.05 . First, a two-way ANOVA with repeated measures test was analysed to find out the effect of the road lighting intensities and the glare on the detection distances. Independent variables were the presence or absence of glare and the road lighting levels (100, 71, and 49\%). The dependent variable was detection distance. The null hypotheses in this test were:

Hypothesis 1 (null): there was no difference in the detection distances under different road lighting intensities.

Hypothesis 2 (null): there was no difference in the detection distances in presence or absence of glare from oncoming car headlights.

Hypothesis 3 (null): there was no interaction between different road lighting intensities and presence or absence of glare.

The results indicated that there was a significant difference in the detection distances under different road lighting intensities $\left(\mathrm{F}(2,16)=6.49, p=0.009, \eta_{p}^{2}=0.45\right)$. There was no significant difference between detection distance in the presence or absence of glare of oncoming car headlights $\left(\mathrm{F}(1,8)=3.58, p=0.095, \eta_{p}^{2}=0.31\right)$. However, the interaction of car headlights (glare vs. no glare) and road lightings was significant $\left(\mathrm{F}(2,16)=3.705, P=0.048, \eta_{p}^{2}=0.317\right)$.

Having a significant effect of the road lighting and significant interactions, a further analysis was made to test the effects of the road lighting in presence or absence of glare. Based on Fig. 3, under full and medium road lighting intensities, there seems to be the only small difference in the mean detection distance due to the presence or absence of glare. A noticeable difference can be observed under the lowest road lighting intensity. There is, therefore, a need for an extra test 
Table 3 Contrast in no glare/glare scenarios calculated for each detection distance (for glare scenario age factor is applied for each driver)

\begin{tabular}{|c|c|c|c|}
\hline Glare/no glare & Road lighting (\%) & Distances(m) & Contrast \\
\hline \multirow[t]{15}{*}{ No glare } & \multirow[t]{5}{*}{$100 \%$} & 109.5 & $(-) 0.027$ \\
\hline & & 84.6 & $(+) 0.151$ \\
\hline & & 116.2 & $(-) 0.102$ \\
\hline & & 92.3 & $(+) 0.077$ \\
\hline & & 130.9 & $(-) 0.153$ \\
\hline & \multirow[t]{5}{*}{$71 \%$} & 95.6 & $(+) 0.071$ \\
\hline & & 79.5 & $(+) 0.236$ \\
\hline & & 103.8 & $(+) 0.061$ \\
\hline & & 81.5 & $(+) 0.216$ \\
\hline & & 106.5 & $(+) 0.005$ \\
\hline & \multirow[t]{5}{*}{$49 \%$} & 138.3 & $(-) 0.120$ \\
\hline & & 108.9 & $(-) 0.017$ \\
\hline & & 119 & $(-) 0.120$ \\
\hline & & 107.3 & $(-) 0.013$ \\
\hline & & 112.5 & $(-) 0.018$ \\
\hline \multirow[t]{15}{*}{ Glare } & \multirow[t]{5}{*}{$100 \%$} & $92.9(50 \mathrm{y} / 0)$ & $(-) 0.014$ \\
\hline & & $75.15(30 y / o)$ & $(-) 0.002$ \\
\hline & & $105.2(30 \mathrm{y} / \mathrm{o})$ & $(-) 0.022$ \\
\hline & & $103(30 y / o)$ & $(-) 0.022$ \\
\hline & & $98.9(50 \mathrm{y} / 0)$ & $(-) 0.012$ \\
\hline & \multirow[t]{5}{*}{$71 \%$} & $93.7(50 \mathrm{y} / 0)$ & $(-) 0.009$ \\
\hline & & $73.35(30 \mathrm{y} / \mathrm{o})$ & $(-) 0.020$ \\
\hline & & $91.7(30 \mathrm{y} / 0)$ & $(-) 0.009$ \\
\hline & & $102.8(30 \mathrm{y} / \mathrm{o})$ & $(-) 0.015$ \\
\hline & & $73.65(50 \mathrm{y} / \mathrm{o})$ & $(-) 0.016$ \\
\hline & \multirow[t]{5}{*}{$49 \%$} & $81.45(50 \mathrm{y} / \mathrm{o})$ & $(-) 0.001$ \\
\hline & & $65.15(30 \mathrm{y} / \mathrm{o})$ & $(-) 0.070$ \\
\hline & & $101.5(30 \mathrm{y} / \mathrm{o})$ & $(-) 0.020$ \\
\hline & & $98(30 y / 0)$ & $(-) 0.017$ \\
\hline & & $104.8(50 \mathrm{y} / \mathrm{o})$ & $(-) 0.017$ \\
\hline
\end{tabular}

for the effect of glare under different road lighting intensities. The independent variable for this test was the presence or absence of glare. One lighting intensity was used in each test. The dependent variable was the detection distance. The results indicate a significant difference in the detection distances due to the presence or absence of glare under $100 \%\left(\mathrm{~F}(1,4)=245.7, p=0.000, \eta_{p}^{2}=0.984\right)$ and $49 \%$ $\left(\mathrm{F}(1,4)=21.44, p=0.010, \eta_{p}^{2}=0.843\right)$ of road lighting intensity. Detection distances under glare were lower at $71 \%$ road lighting intensity, but the difference was not statistically significant $\left(\mathrm{F}(1,4)=0.664, p=0.461, \eta_{p}^{2}=0.142\right)$.

Another ANOVA with repeated measures was conducted to test the effect of various lighting levels on detection distance in the no-glare scenario. The independent variable was road lighting levels $(100,71$, and $49 \%)$ and the dependent variable was detection distance. The null hypothesis was that the average detection distance was equal in all road lighting levels, and the result was significant $(\mathrm{F}(2,8)=9.561$, $\left.p=0.008, \eta_{p}^{2}=0.705\right)$. The pairwise t-test comparison indicates that a significant main effect was between road lighting levels 71 and 49\%; (t(4) $=-3.807, p=0.019)$ but not between 100 and $71 \% ;(\mathrm{t}(4)=2.261, p=0.087)$. There was a near significant difference between 100 and $49 \%(\mathrm{t}(4)=-2.659$, $p=0.056$ ). This indicates that in no-glare conditions $49 \%$ of road lighting intensity provided best (or at least as good as $100 \%)$ illumination for detecting targets on the road. However, the effect of dimming appears not to be monotonic.

Finally, an ANOVA test for the effect of various lighting levels on detection distance in the presence of glare was conducted. The independent variable was road lighting levels $(100,71$, and $49 \%)$ and the dependent variable was detection distance. The null hypothesis was that the average detection distance was equal in all road lighting levels. The result was not significant $\left(\mathrm{F}(2,8)=1.612, p=0.26, \eta_{p}^{2}=0.287\right)$.

\section{Discussion}

Until recently, not many studies have been conducted about the interaction between road lighting and car headlights, despite the high potential to reduce energy consumption by dimming road lighting. The functions of road lighting and car headlights are complementary, but a combination of them may not be effective under all conditions. In addition, no research has been found about the influence of different road lighting intensities on the detection distances of targets on the road.

The purpose of this study was to determine the combined effect of car headlights and different road lighting intensities on detection distances of a standard target while driving on a straight road in presence or absence of glare from an oncoming car. The significance of differences was determined by ANOVA. The results indicated that the effect of lighting levels on detection distances in no glare scenario was significant. The significant main effect was between 49 and $71 \%$ of road lighting intensities. Under glare, detection distances were highest at $100 \%$ lighting intensity, but the difference was not statistically significant. Targets were detected at shorter distances in the presence of glare compared to the no glare scenarios, but different road lighting intensities did not have a significant effect on the detection distance whenever the glare was present.

Another important result to emerge from no glare experiments was that reducing road lighting intensity level to $49 \%$ (3557 lm) will result in detection distances comparable, if not better than, with full road lighting intensity $(7252 \mathrm{~lm})$. The results indicated that reducing road lighting intensity does not monotonically affect the detection distance. For example, $71 \%$ of the road lighting intensity $(5179 \mathrm{~lm})$ resulted in a shorter mean detection distance than $49 \%$. However, the study was conducted under the same road characteristics and only one- 
Fig. 4 Vertical illuminance (lx) at different distances from car considering both car headlights and road lighting. In off situation, only the effect of car headlights is considered

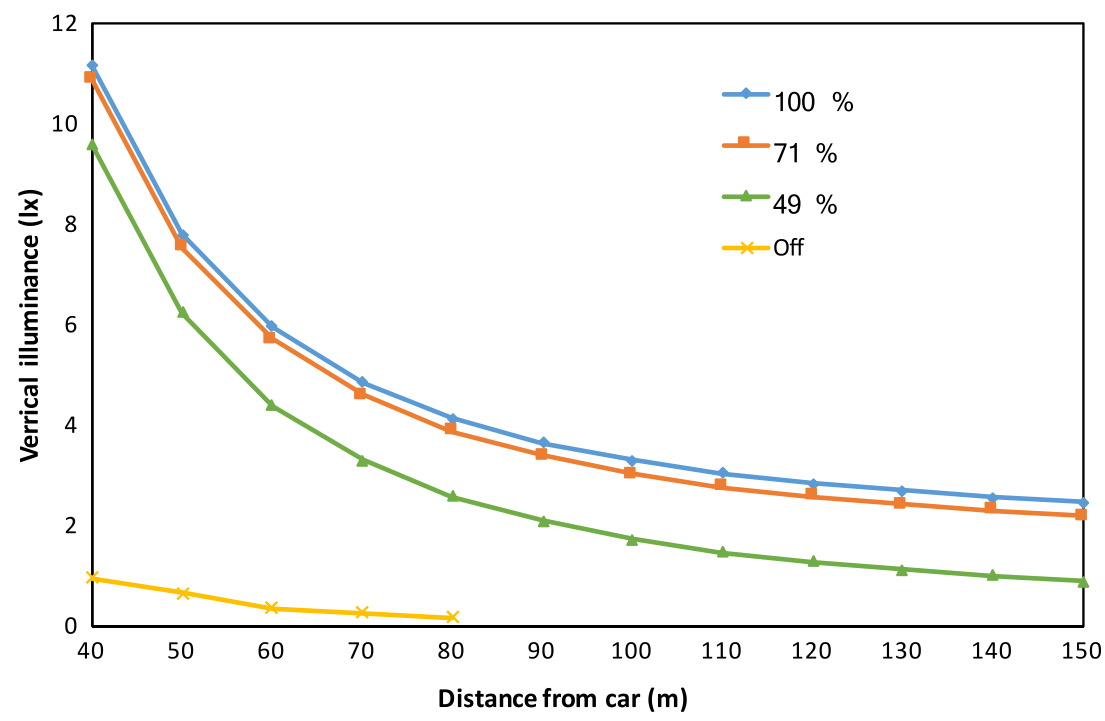

speed limit. Additional measurements are needed to assess the current outcome in varying speed limits and road characteristics.

This study on the combined effect of dimmed road lighting intensities and car headlights in a moving car correlates well with the study using a stationary car [7]. Both studies indicate that road lighting can be dimmed when car headlights are used. Glare from the oncoming car reduced the visual performance of drivers, but in this study, the effect of glare from an oncoming car under different road lighting levels on detection distances was not statistically significant.

It can be seen that when driving from far distance, targets should be detected first in negative contrast and then at some point it will be merged with the background (road) and then appear in positive contrast. Additionally, full road lighting is more beneficial in detecting targets in negative contrast in the far zone while approaching the target reduces the effect of full road lighting. On the other hand, reducing road lighting, in this case by $49 \%$, reduces the effect of road lighting in the far zone while increases the effect of car headlights in intermediate and near zones.

Assum et al. [3] indicated that some drivers increase their speeds in comparison with other drivers who drive more slowly after the installation of road lights and these counterbalanced driving speeds may increase accident risk
Fig. 5 Positive and negative contrast in different distances from car headlights under different road lighting intensities

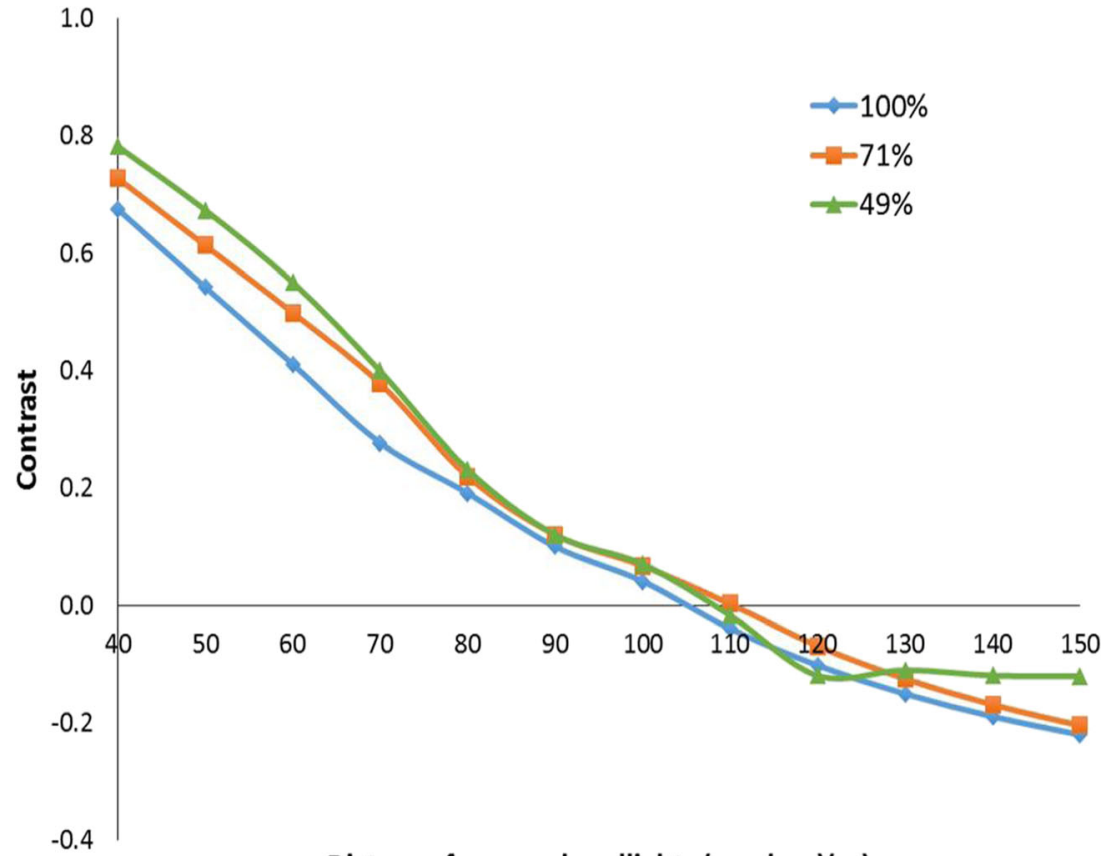

Distance from car headlights (no glare)(m) 
[3]. Therefore, according to the results of the current study, drivers could be expected to reduce speed and increase concentration during low road lighting intensity. Also, lighting conditions enabling the target detection at longer distances can be assumed to improve safety, assuming that drivers do not increase speeds under better but dimmer lighting conditions. These safety effects require further study.

The research had some limitations: It was limited by its small sample size. However, the results obtained were consistent internally and with previous work. One reflection factor for the target, limited intensity levels from road lighting intensities (100, 71, and 49\%), and one-speed limit caused some additional limitations. The road geometry had a slight vertical curve so that the detection distances may be slightly underestimated. This can be both a positive and a negative factor in the measurements. If the road was straight and uniform, the drivers' eyes could have been fixed to the target position, and repeating the measurements would affect the detection distance. Now due to the curvature the drivers had to wait until they actually saw the target. On the other hand, drivers' vision was affected by the height of drivers (ranged from 158 to $189 \mathrm{~cm}$ ). The target became visible gradually according to the height of drivers. Because the same drivers were used to all scenarios, the height difference had the same effect in all lighting conditions. Although different heights may have had an effect on the target detection distance, the changes in detection distances due to changes in lighting levels within each driver were consistent. The observed detection distances may be shorter than on a level roadway, but the results about the effects of lighting conditions are consistent.

\section{Conclusion}

Numerous reasons highlight the importance of the transition from standard static road lighting practices to intelligent road lighting ones, such as the cost and environmental impacts of light. This study indicates that current road lighting practices are over-lighting and there are potentials to reduce road lighting levels in the presence of car headlights. Since the correlation between road lighting and car headlights is not complementary in making contrast, reducing road lighting to certain level increases the effect of car headlights.

Acknowledgements This research was supported by the following institutions: the Aalto Energy Efficiency Research Programme (the "Light Energy_Efficient and Safe Traffic Environments" project); the Academy of Finland, the Centre of Excellence in Laser Scanning Research (CoE-LaSR, project number 272195), the Strategic Research Council project COMBAT (No. 293389). Our special thanks go to our colleague, Åsa Enberg, who helped us with traffic safety arrangements. The authors also acknowledge the city of Espoo for giving us the opportunity to dim the lights in a section of Otaranta road.
Open Access This article is distributed under the terms of the Creative Commons Attribution 4.0 International License (http:// creativecommons.org/licenses/by/4.0/), which permits unrestricted use, distribution, and reproduction in any medium, provided you give appropriate credit to the original author(s) and the source, provide a link to the Creative Commons license, and indicate if changes were made.

\section{References}

1. Adrian W, Bhanji A (1991) Fundamentals of discomfort glare: a formula to describe straylight in the eye as a function of glare angle. Proceedings of the 1st International Symposium on Glare 185-194

2. AASHTO $(2010,2014)$ Highway safety manual (1st Edition) with supplement 2014. American Association of State Highway and Transportation Officials (AASHTO). Online version available at: http://app.knovel.com/hotlink/toc/id:kpHSM00002/highwaysafety-manual/highway-safety-manual

3. Assum T, Bjornskau T, Fosser S, Sagberg F (1999) Risk compensation- the case of road lighting. J Accid Anal Prev 31: 545-553

4. Bacelar A (2004) The contribution of vehicle lights in urban and peripheral urban environments. J Light Res Technol 36:69-78

5. Bacelar A (2005) The influence of dimming in road lighting on the visibility of drivers. J Light Vis Environ 29:44-49

6. Boyce PR (2008) Lighting for driving: roads, vehicles, signs and signals. Taylor \& Francis Group, CRC Press, New York

7. Bozorg Chenani S, Maksimainen M, Tetri E, Kosonen I, Luttinen $\mathrm{T}$ (2016) The effect of dimmable road lighting: a comparison of measured and perceived visibility. J Transport Res FTRAF 43:141-156

8. Commission Internationale de l'Eclairage, CIE (1993) Road lighting as an accident countermeasure. International Commission on Illumination, Vienna, Publication NO. 93

9. Commission Internationale de l'Eclairage, CIE (2010) Lighting of roads for motor and pedestrian traffic, Vienna, Technical Report NO 115

10. Ekrias A, Eloholma M, Halonen L (2008) The contribution of vehicle headlights to visibility of targets in road lighting environments. Int Rev Elect Eng (I.R.E.E) 3:208-217

11. Elvik R, Vaa T (2009) The handbook of road safety measures second edition. Elsevier Ltd. ISBN: 978-1-84855-250-0, Oxford

12. Gibbons R, Meyer J, Terry T, Bhagavathula R, Lewis A, Flanagan M, Connell C (2015) Evaluation of impact of spectral power distribution on driver performance. Report No. FHWA-HRT-15-047

13. IEA (Light's Labour Lost) Policies for energy efficient lighting (2006) [online] Available at: https://www.iea.org/publications/ freepublications/publication/light2006.pdf. Accessed 10 Nov 2015

14. Johansson G, Rumar K (1968) Visible distance and safe approach speeds for night driving. J Ergonomics 3:275-282

15. Mace D, Garvey P, Porter RJ, Scwab R, Adrian W (2001) Countermeasures for reducing the effects of headlight glare. AAA Foundation for Traffic Safety. [online] Available at: https://trid.trb. org/view.aspx?id=707950. Accessed 7 Dec 2016

16. Massie DL, Campbell KL (1993) Analysis of accident rates by age, gender, and time of day based on the 1990 Nationwide Personal Transportation Survey. Technical report. Report No. UMTRI-93-7

17. Mayeur A, Bremond R, Christian Bastien JM (2010) The effect of the driving activity on target detection as a function of the visibility level: implications for road lighting. J Transport res F-TRAF 13: $115-128$ 
18. Peli E (1990) Contrast in complex images. J Opt Soc Am A 10: 2032-2040

19. Plainis S, Murray IJ, Pallikaris IG (2006) Road traffic casualties: understanding the night- time death toll. J Inj Prev 2:125-128

20. Rea MS, Bullough JD, Zhou Y (2010) A method for assessing the visibility benefits of roadway lighting. J J Light Res Technol 42: 215-241
21. WHO, World Health Organization (2014) The top 10 causes of deaths Available at: http://www.who.int/mediacentre/factsheets/ fs310/en/

22. Wortman RH, Mathias JS (1983) Evaluation of driver behavior at signalized intersections. Transp. Res. Rec, 904, Washington, D.C. 